\title{
Incidence of Post-Operative Venous Thromboembolism Using Compression Ultrasonography Following Trauma to Spine and Long Bones of Lower Extremity
}

\author{
Nitin Gupta, Rakesh Bahrgava \\ Department of Orthopaedics, National Institute of Medical Sciences, Jaipur, India. \\ Email: nitingupta9@hotmail.com,drrakeshbhargava@hotmail.com
}

Received March 12 $2^{\text {th }}, 2013$; revised May $1^{\text {st }}, 2013$; accepted May $16^{\text {th }}, 2013$

Copyright (c) 2013 Nitin Gupta, Rakesh Bahrgava. This is an open access article distributed under the Creative Commons Attribution License, which permits unrestricted use, distribution, and reproduction in any medium, provided the original work is properly cited.

\begin{abstract}
Background: Venous thromboembolism is an important and potentially a fatal complication if not suspected and treated promptly. Various diagnostic modalities are available to detect Deep Vein Thrombosis (DVT), but each has its merits and demerits. Compression ultrasonography is a non-invasive method to diagnose DVT. This study was undertaken to evaluate the incidence of DVT using compression ultrasonography in the patients who underwent surgery of the spine and long bones of lower extremity following trauma. Material \& Methods: All patients who underwent surgery following trauma to the spine and long bones of lower extremity were screened using Venous B-mode ultrasonography and color Doppler imaging. None of the patients received prophylaxis against DVT. The patients were selected on the basis of the following findings: 1) Immediately in patients found to have clinical DVT following surgery; 2) Every odd number of patients who underwent surgery and did not show signs and symptoms of DVT on the $7^{\text {th }}, 14^{\text {th }}$ post operative day and $6^{\text {th }}$ post operative week. Results: The incidence of DVT using compression ultrasonography in the patients who underwent surgery of the spine and long bones of lower extremity following trauma was 17 percent. The incidence of DVT has no correlation with various clinical variables. Conclusion: The observed incidence of DVT is reasonably high and it is a potential risk factor for the development of pulmonary embolism.
\end{abstract}

Keywords: Deep Vein Thrombosis; Compression Ultrasonography; Trauma

\section{Introduction}

Venous thromboembolism, which includes deep vein thrombosis and Pulmonary Embolism (PE), is an important and potentially a fatal complication of patients sustaining traumatic fractures of the spine and long bones of the lower extremity if not suspected and treated promptly. The triad of conditions associated with the development of deep vein thrombosis includes intimal injury, stasis and hypercoagulability. All the three conditions are frequently seen in trauma patients soon after injury. Intimal injury may be present as a result of direct tissue destruction of venous blood vessel walls from the inciting traumatic event. Stasis may occur as a result of paralysis, immobilization or decreased blood flow caused by haemorrhagic shock. The clinical signs and symptoms of deep vein thrombosis include pain, swelling of limbs, pain on calf compression (Moses sign), pain on dorsiflexion of the ankle (Homan's sign) etc. It remains one of the commonest causes of preventable hospital deaths in western world $[1,2]$. The reported sensitivity and specificity of clinical findings do not exceed a very disappointing figure of $50 \%[3,4]$. Contrast venography remains the reference with which all the other tests have to be compared. It is invasive, sometimes painful to the patient and associated with contrast media systemic complications [5]. In addition, the thrombogenic properties of the latter can cause venography to initiate thrombosis, thus produce the very change. It is designed to detect the post phlebographic syndrome. The radioactive fibrinogen test is accurate, quick and simple. However, the disadvantage of the method is that there is a $6-24$ hour delay before the count is of diagnostic value. The second disadvantage is that by using this method of screening, it is difficult to select those patients who need treatment. The third disadvantage is that the test carries the risk of hepatitis because of administration of fibrinogen. Since impedance plethysmography is an indirect physiological test that depends on abnormalities in ve- 
nous outflow, it may produce false positive IPG examination.

Duplex ultrasonography of leg veins is being used more and more in clinical practice as a diagnostic tool for diagnosing deep vein thrombosis. Ultrasound scanning has the advantage as a screening tool in detecting deep vein thrombosis, because it is non-invasive, requires no contrast media and can be performed at the bedside and is liable to detect non-occlusive thrombus.

The incidence of venous thromboembolism in patients with traumatic fractures of long bones of lower extremity and spine after surgical intervention is reported to be higher in western population than in Asian patient population [6-8]. The reported incidence varies from $45 \%$ to $84 \%$ and about $1 \%$ - $2 \%$ of these develop fatal pulmonary embolism $[7,8]$. However, amongst the Asian population, the reported figures on the incidence of deep vein thrombosis are variable and it is presumed that the Indian patient population has a very low incidence of deep vein thrombosis if any [6,9]. Thus it is important to study the incidence of subclinical deep vein thrombosis in operated Indian population. There are very few studies that have been conducted to know the incidence of post-operative deep vein thrombosis in Indian patients after surgery for trauma to the spine and long bones of the lower extremity. Hence a prospective observational study was conducted in order to evaluate the incidence of deep vein thrombosis in post-operative patients following trauma to the spine and long bones of lower extremity using compression ultrasonography

\section{Material and Methods}

One hundred patients operated for trauma to spine and long bones of lower extremity were screened in the present study. All these patients were evaluated by detailed history and physical examination focusing on demographic data, details related to trauma, fracture site, duration of trauma and predisposing factors to venous thromboembolism, e.g. obesity, immobilization, smoking etc. History was also gathered for any symptoms and or signs of PE, e.g. shortness of breath, chest pain, hemoptysis, etc. Clinical examination included recording of blood pressure and signs of PE. Detailed examination was done to look for any evidence of deep vein thrombosis, e.g. swelling, pain, increased temperature, Mose's sign, Homan's sign and thigh \& calf circumference. Laboratory investigation included blood sugar, blood urea, serum creatinine, hemoglobin, arterial blood gas analysis and electrocardiogram in all patients.

All the patients were mobilized on the $2^{\text {nd }}$ post operative day.

B-Mode and color flow Doppler imaging of lower ex- tremity venous system was done using 5 - $10 \mathrm{MHz}$ broad band linear probe of ATL HDI 3000 echo machine:

1) Immediately in patients found to have clinical deep vein thrombosis following surgery.

2) Every odd number of patient who underwent surgery and did not show signs and symptoms of deep vein thrombosis on the $7^{\text {th }}, 14^{\text {th }}$ post operative day and $6^{\text {th }}$ post operative week.

The ultrasound gel was used as the couplant. The patients were placed supine with the legs in external rotation to evaluate the common femoral and deep femoral vein from inguinal ligament to the adductor hiatus in both longitudinal and transverse orientation. The popliteal vein evaluation in case of total hip arthroplasty patients was done in thirty degree reverse Trendlenberg's position with the knees flexed to twenty degrees rather than the usual prone position because it may produce discomfort to the patient and might be associated with dislocation of hip. In case of total knee replacement and other surgeries, patients were made to lie prone. The iliac and calf veins were not studied because viewing these is technically difficult. The ultrasound was considered normal if the femoral and popliteal veins were visible and could be compressed completely by application pressure with the transducer probe while the lumen of vein was observed on the real time image. The finding of the echogenic thrombus was also noted but complete compressibility of the vein was the strict criterion for the absence of the thrombus.

As none of the patients evaluated showed signs \& symptoms of PE, Echo Doppler study was not done.

Patients were divided into two groups based on the presence or absence of deep vein thrombosis. Quantitative discreet variables were compared as percentage and analyzed using student's t-test. Multivariate logistic regression analysis was used to assess the independent predictive value of each clinical variable for deep vein thrombosis. Probability value (p value) less than 0.05 was taken as significant.

\section{Results}

Tables 1, 2 and $\mathbf{3}$ show that all the factors such as age, sex, smoking, blood pressure, waist circumference, duration of trauma likely to influence the incidence of deep vein thrombosis are comparable ( $\mathrm{p}$ value $>0.05$ ). In the present study $17 \%$ patients were detected to have deep vein thrombosis. None of the patients with ultrasonic evidence of deep vein thrombosis were symptomatic.

Out of 17 patients who had ultrasonic evidence of deep vein thrombosis, one or more clinical signs of deep vein thrombosis (swelling of legs, Homan's sign, Mose's sign) were present in $64.71 \%$ of patients with deep vein 
Table 1. Demographic data.

\begin{tabular}{clccc}
\hline Sr. No. & \multicolumn{1}{c}{ Variables } & Patients with DVT & Patients without DVT & p-Value \\
\hline & (N = Total No.) $\mathbf{N}=\mathbf{1 0 0}$ & $\mathbf{N}=17$ & $\mathbf{N}=\mathbf{8 3}$ & \\
1 & (Years) $($ Mean \pm S.D.) & $\mathbf{4 6 . 0 6} \pm \mathbf{2 0 . 6 8}$ & $42.80 \pm 17.57$ & 0.500 \\
2 & GENDER (No.; \%) & & & 0.652 \\
(a) & Male $(\mathbf{N}=\mathbf{7 2})$ & $\mathbf{1 3 ~ ( 1 8 . 0 6 )}$ & $59(81.94)$ & \\
(b) & Female $(\mathbf{N}=\mathbf{2 8})$ & $\mathbf{4 ( 1 4 . 2 9 )}$ & $24(84.71)$ & \\
\hline
\end{tabular}

p-value $\leq 0.01$ at $\alpha=0.01$ or $1 \%$, p-value between 0.01 and 0.05 at $\alpha=0.05$ or $5 \%$.

Table 2. Risk factors.

\begin{tabular}{|c|c|c|c|c|}
\hline Sr. No. & Variables & Patients with DVT & Patients without DVT & p-Value \\
\hline & $(N=$ Total No. $) N=100$ & $\mathrm{~N}=17$ & $\mathbf{N}=\mathbf{8 3}$ & \\
\hline 1 & H/O SMOKING (No.; \%) & & & 0.493 \\
\hline (a) & Smokers $(\mathbf{N}=\mathbf{3 4})$ & 7 (20.59) & $27(79.41)$ & \\
\hline (b) & Non-smokers $(\mathbf{N}=\mathbf{6 6})$ & $10(15.51)$ & 56 (84.49) & \\
\hline
\end{tabular}

p-value $\leq 0.01$ at $\alpha=0.01$ or $1 \%$, $p$-value between 0.01 and 0.05 at $\alpha=0.05$ or $5 \%$.

Table 3. Clinical examination.

\begin{tabular}{clccc}
\hline Sr. No. & \multicolumn{1}{c}{ Variables } & Patients with DVT & Patients without DVT & p-Value \\
\hline & (N= Total No.) $\mathbf{N}=\mathbf{1 0 0}$ & $\mathrm{N}=17$ & $\mathbf{N}=\mathbf{8 3}$ & \\
1. & $\begin{array}{l}\text { Waist circumference }(\mathrm{cm}) \\
\text { (Mean } \pm \text { S.D.) }\end{array}$ & & & \\
(a) & Male & $\mathbf{8 0 . 6 2} \pm \mathbf{2 . 0 6}$ & $78.86 \pm 8.47$ & 0.464 \\
(b) & Female & $\mathbf{8 0 . 5 0} \pm \mathbf{1 . 2 9}$ & $79.46 \pm 4.85$ & 0.678 \\
2. & Blood pressure & & & \\
(a) & Systolic & & & 0.527 \\
(b) & Diastolic & $\mathbf{1 2 6 . 9 4} \pm \mathbf{1 5 . 9 7}$ & $124.72 \pm 12.51$ & 0.679 \\
\hline
\end{tabular}

p-value $\leq 0.01$ at $\alpha=0.01$ or $1 \%$, p-value between 0.01 and 0.05 at $\alpha=0.05$ or $5 \%$.

Table 4. Clinical examination.

\begin{tabular}{|c|c|c|c|}
\hline Sr. No. & Variables & Patients with DVT & Patients without DVT \\
\hline & $(\mathrm{N}=$ Total No. $) \mathrm{N}=100$ & $\mathrm{~N}=17$ & $\mathbf{N}=83$ \\
\hline 1 & Swelling of lower limb (No.; \%) & & \\
\hline (a) & Present $(\mathrm{N}=14)$ & 11 (78.57) & $3(21.43)$ \\
\hline (b) & Absent $(\mathbf{N}=\mathbf{8 6})$ & $6(6.98)$ & $80(93.02)$ \\
\hline 2 & Temperature (No.; \%) & & \\
\hline (a) & Raised $(\mathbf{N}=\mathbf{6})$ & $6(100)$ & $0(0)$ \\
\hline (b) & Not raised $(\mathbf{N}=\mathbf{9 4})$ & $11(11.70)$ & $83(88.30)$ \\
\hline 3 & Mose’s sign (No.; \%) & & \\
\hline (a) & Present $(\mathbf{N}=12)$ & $10(83.33)$ & $2(16.67)$ \\
\hline (b) & Absent $(\mathbf{N}=\mathbf{8 8})$ & $5(5.68)$ & $83(94.32)$ \\
\hline 4 & Homan’s sign (No.; \%) & & \\
\hline (a) & Present $(\mathbf{N}=13)$ & $10(76.92)$ & $3(23.08)$ \\
\hline (b) & Absent ( $\mathbf{N}=\mathbf{8 7})$ & $7(8.05)$ & 80 (91.95) \\
\hline
\end{tabular}


Table 5. Duration of trauma.

\begin{tabular}{|c|c|c|c|}
\hline Sr. No. & Variables & Patients with DVT & Patients without DVT \\
\hline & $(\mathrm{N}=$ Total No. $) \mathrm{N}=100$ & $\mathrm{~N}=17$ & $\mathbf{N}=\mathbf{8 3}$ \\
\hline 1. & $\begin{array}{l}\text { Duration of trauma (days) } \\
\text { (Mean } \pm \text { S.D.) }\end{array}$ & $43.76 \pm 69.38$ & $34.34 \pm 56.26$ \\
\hline
\end{tabular}

Table 6. Type of anaesthesia.

\begin{tabular}{clcc}
\hline Sr. No. & \multicolumn{1}{c}{ Variables } & Patients with DVT & Patients without DVT \\
\hline & $(\mathbf{N}=$ Total No.) $\mathbf{~}=\mathbf{1 0 0}$ & $\mathrm{N}=17$ & $\mathbf{N}=\mathbf{8 3}$ \\
1. & Spinal anaesthesia $(\mathbf{N}=\mathbf{8 4})($ No.; $\%)$ & $\mathbf{1 4}(\mathbf{1 6 . 6 7 )}$ & $70(83.33)$ \\
2. & General anaesthesia $(\mathbf{N}=\mathbf{1 6})($ No.; \%) & $\mathbf{3}(\mathbf{1 8 . 7 5 )}$ & $13(81.25)$ \\
\hline
\end{tabular}

thrombosis against $35.29 \%$ patients with deep vein thrombosis who showed no sign of deep vein thrombosis (Table 4).

Duration of trauma before surgery was longer in patients with deep vein thrombosis compared to those without deep vein thrombosis. The difference was not statistically significant (Table 5). The patients who underwent surgery under spinal anaesthesia had deep vein thrombosis in $18.75 \%$ as opposed to $16.67 \%$ of the patients who were operated under general anaesthesia (Table 6).

\section{Discussion}

Reviewing the world literature, the incidence of deep vein thrombosis shows great variations.

Agarwal and co-workers (2003) [8] reported 60\% of the patients who did not receive thromboprophylaxis and $43.2 \%$ of the patients who received thromboprophylaxis developed deep vein thrombosis.

Grandy Benson \& co-workers (1994) [10] reported 21.8\% prevalence of deep vein thrombosis in their series of 51 patients using compression ultrasonography who underwent total hip arthroplasty and all patients received prophylaxis. Froehlic, et al (1989) [11] reported a prevalence of $12.5 \%$ using venography in patients undergoing THA for fractures around hip with thromboprophylaxis.

Dhillon and co-workers (1996) [12] reported that 55 patients with venographic evidence of deep vein thrombosis $34.5 \%$ had one or more clinical signs of deep vein thrombosis.

Dhillon and co-workers (1996) [12] in their study observed that $58.3 \%$ patients operated under spinal anaesthesia and $67.5 \%$ operated under general anaesthesia developed deep vein thrombosis.

In our study the incidence of deep vein thrombosis was $17 \%$ (17 out of total of 100 patients developed deep vein thrombosis). None of the patients found to have ultrasonic evidence of DVT were symptomatic. $64.71 \%$ of patients found to have DVT had one or more clinical sign of DVT, i.e., swelling, Homan's sign, Mose's sign and $34.29 \%$ of the patients with DVT had no clinical signs of DVT.

The sensitivity and specificity of Mose's sign in the diagnosis of DVT was $66.67 \%$ and $97.65 \%$ respectively whereas the sensitivity and specificity of Homan's sign was $58.82 \%$ and $96.39 \%$ respectively.

The incidence of DVT had no correlation with various clinical variables, e.g. age, sex, smoking, waist circumference, blood pressure, blood sugar, site of trauma, duration of trauma, type of surgery, type of anaesthesia and post-operative immobilization.

The arterial saturation and $\mathrm{pO}_{2}$ in patients with DVT was lower suggesting possibility of silent pulmonary embolism in some patients.

The other investigators (Agarwal et al. [8] and Grandy Benson et al. [10]) either used contrast venography, which has a higher sensitivity, as the diagnostic modality or the study population was elderly who underwent high risk procedures such as total hip arthroplasty and total knee arthroplasty. This may be the reason for higher incidence of deep vein thrombosis in their study as compared to our study.

As a general practice anti-inflammatory/analgesic agents were prescribed to all the patients for a period of 7 - 10 days. This may be the reason why none of the patients experienced pain, which is an important symptom of deep vein thrombosis.

The present study was not designed to test the impact of anaesthesia on the prevalence of deep vein thrombosis as the type of anaesthesia given was not randomized.

\section{Conclusions}

The Results of the study showed that the incidence of deep vein thrombosis in post-operative patients following trauma to spine and long bones of lower extremity was $17 \%$.

Since the observed incidence of deep vein thrombosis was reasonably high and it was a potential risk factor for 
the development of pulmonary embolism, the present practice of withholding routine prophylaxis in patients undergoing high risk surgeries for trauma to spine and long bones of lower extremity should be reconsidered.

Further controlled trials with a large number of patients are required to determine the incidence of deep vein thrombosis and/or pulmonary embolism in patients undergoing surgery for trauma to spine and long bones of lower extremity and to identify the characteristics of patients with trauma that may be associated with high risk of thromboembolic complications.

\section{REFERENCES}

[1] R. A. Hull and G. E. Raskob, "Prophylaxis of Venous Thromboembolic Disease Following Hip and Knee Surgery," The Journal of Bone and Joint Surgery, Vol. 68, No. 1, 1986, pp. 146-150.

[2] E. A. Salvati, V. D. Pellegrini Jr., N. E. Sharrock, et al., "Recent Advances in Thromboembolic Prophylaxis during and after Total Hip Replacement," The Journal of Bone and Joint Surgery, Vol. 82, No. 2, 2000, pp. 252270.

[3] K. Haeger, "Problem of Acute Venous Thromboembosis: The Interpretation of Signs and Symptoms," Angiology, Vol. 20, No. 4, 1969, pp. 219-223. doi:10.1177/000331976902000406

[4] J. J. Granley, A. J. Canes and W. J. Sull, "Diagnosis of Deep Vein Thrombosis: Falliability of Clinical Symptoms and Signs," Archives of Surgery, Vol. 111, No. 1, 1996, pp. 34-36. doi:10.1001/archsurg.1976.01360190036005

[5] M. A. Bettman and S. Pantin, "Leg phlebography: The Incidence, Nature and Modification of Undesirable Side
Effects,” Radiology, Vol. 122, No. 1, 1977, pp. 101-104.

[6] L. F. Tinkler, “Absence of Pulmonary Embolism in Asians?” British Medical Journal, Vol. 1, No. 5381, 1964, p. 502. doi:10.1136/bmj.1.5381.502-c

[7] B. N. Stulberg, J. N. Inrals, G. W. Williams and B. Ghalman, "Deep Vein Thrombosis Following Total Knee Replacement: An Analysis of Six Hundred and Thirty Eight Arthroplasties," Journal of Bone and Joint Surgery, Vol. 66, No. 2, 1984, pp. 194-201.

[8] S. Agarwal, A. Bhagwat, J. Modhe, F. D. Dastur and S. Patil, "Incidence of Deep Vein Thrombosis in Indian Patients,” Indian Journal of Orthopaedics, Vol. 37, No. 2, 2003, pp. 98-102.

[9] C. K. Mok, F. T. Hoaglund and S. M. Rogoff, “The InciDence of Deep Vein Thrombosis in Hong Kong Chinese Afterhip Surgery for Fracture of the Proximal Femur," British Journal of Surgery, Vol. 66, No. 9, 1979, pp. 640642. doi:10.1002/bjs.1800660914

[10] J. C. Grady-Benson, C. S. Oishi, et al., "Routine Post Operative Duplex Ultrasonography Screening and Monitoring for the Detection of Deep Vein Thrombosis," Clinical Orthopaedics and Related Research, No. 307, 1994, pp. 130141.

[11] J. A. Froehlic, G. S. Dorfman, J. J. Cronan, P. J. Urbank, H. Herndon and A. R. K. Aaron, "Compression Ultrasonography for the Detection of Deep Vein Thrombosis in Patients Who Have a Fracture of the Hip,” The Journal of Bone and Joint Surgery, Vol. 71, No. 2, 1989, pp. 249255.

[12] K. S. Dhillon, A. Askender and S. Doraiswamy, "Post Operative Deep Vein Thrombosis in Asian Patients Not a Rarity.” The Journal of Bone and Joint Surgery, Vol. 78, No. 3, 1996, pp. 427-430. 